\section{Military Technical College Kobry El-Kobbah, Cairo, Egypt}

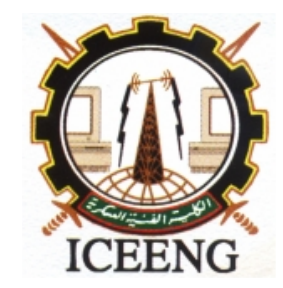

\section{$8^{\text {th }}$ International Conference on Electrical Engineering ICEENG 2012}

\title{
Modeling of Asynchronous machines for stability analysis
}

$$
\text { By }
$$

M. G. S. Zaghloul, M. I. Marei, W. El-Khattam, M.A. L. Badr, H. S. K. El-Goharey

\section{Abstract:}

This paper presents the results obtained when using three different models of the asynchronous machine. The first order model is used to determine the steady-state performance when the rotor of the machine is fed with different direct- and quadrature-axis components of control voltages. The third and fifth order models are simulated and implemented into PSCAD/EMTDC software. These models are used to determine the dynamic behavior of the asynchronous machine when it is connected to an infinite bus and operating with normal conditions. Also, they are used to determine the performance when the induction machine is subjected to three-phase symmetrical faults.

\section{Keywords:}

Induction machine, Modeling, Steady-state performance, Dynamic behavior, Doubly fed induction machine.

Faculty of Engineering, Ain Shams University, Egypt 


\section{Introduction:}

The investigation of dynamic performance of power systems includes the proper modeling of single machines. Simple approaches are needed to make the computational effort acceptable, but the choice of accuracy level to which the model must confirm is a critical point. It represent has been a common practice to electrical machines by sources of constant voltage magnitude connected to the network through constant impedances. This classical representation has certain limitations as it is not applicable to dynamic studies where interest focuses on system stability and damping of oscillations.

Several studies [1-3] have shown that the accuracy of the results of stability analysis and the conclusions drawn therefrom depend on the model used to describe the dynamic behavior of electrical machines. These results have also revealed that the effect of a given model structure on the accuracy of stability results is influenced by the machine data used. Therefore, it is common in transient stability studies to represent the machines by models of varying details. For example, the machines located close to the disturbance may be represented by a detailed model, whereas machines located remotely from the disturbance can be simulated by a simple model. Furthermore, the machines at intermediate locations may use still another model.

This paper presents three different models of the asynchronous machine; the $1^{\text {st }}$ order model, the $3^{\text {rd }}$ order model, and the $5^{\text {th }}$ order model. The $1^{\text {st }}$ order model is used to determine the steady-state performance, while the $3^{\text {rd }}$ and $5^{\text {th }}$ order models are used mainly to determine the transient performance of the asynchronous machine. Simulated results are presented to demonstrate the validity of each model.

\section{Mathematical models of the asynchronous machine [1,4,5]:}

Ideal induction machines are usually assumed and may be defined as follows:

(a) Saturation, hysteresis and eddy currents in all magnetic circuits are neglected,

(b) Each machine winding produces a sinusoidally space distributed magneto-motive force,

(c) Symmetric 3-phase stator and rotor windings are considered, and

(d) The effect of slots is neglected.

Based on the preceding assumptions, the performance of the induction machines can be described by a set of equations $[1,4,5]$ in a synchronously rotating d-q frame of reference. In these equations, the motor convention is adopted. 


\subsection{First Order Model [6]:}

This model is the classical machine (steady-state) model, where no electrical transients are involved and only the mechanical dynamics are taken into account. The voltage equations are obtained by using $\frac{d \psi_{d s}}{d t}=\frac{d \psi_{q s}}{d t}=\frac{d \psi_{d r}}{d t}=\frac{d \psi_{q r}}{d t}=0$. Hence,

$$
\left(\begin{array}{c}
V_{d s} \\
V_{q s} \\
V_{d r} \\
V_{q r}
\end{array}\right)=\left(\begin{array}{cccc}
R_{s} & X_{s} & 0 & X_{m} \\
-X_{s} & R_{s} & -X_{m} & 0 \\
0 & s X_{m} & R_{r} & s X_{r} \\
-s X_{m} & 0 & -s X_{r} & R_{r}
\end{array}\right)\left(\begin{array}{c}
I_{d} \\
I_{q s} \\
I_{d} \\
I_{q r}
\end{array}\right)
$$

The torque equation is given by

$T_{e}=\psi_{d r}{ }^{I} q r-\psi_{q r}{ }^{I} d r$

$=\left(-X_{m} I_{d s}+X_{r d r} I_{q r}\right) I_{m}-\left(-X_{m s} I_{r q}+X_{r} I_{q r}\right) I_{d r}$

$=X_{m}\left(I_{q s} I_{d r}-I_{d s} I_{q r}\right)$

The mechanical equation of the induction machine is considered to be in the following form:

$\frac{d \omega_{r}}{d t}=\frac{\mathrm{P}}{J}\left(T_{e}-T_{m}\right)$

$\frac{d \theta_{r}}{d t}=\omega_{r}$

\subsection{Third order Model [7,8]:}

In third order model the stator transient is neglected. (i.e. $\frac{d \psi_{d s}}{d t}=\frac{d \psi_{q s}}{d t}=0$ ). Hence, the voltage equations are given by:

$$
\begin{aligned}
& \psi_{q s}=\left(-v_{d s}+R_{s} i_{d s}\right) / \omega_{s} \\
& \psi_{d s}=\left(v_{q s}-R_{s} i_{q s}\right) / \omega_{s} \\
& \frac{d \psi_{q r}}{d t}=v_{q r}-\left(\omega_{s}-\omega_{r}\right) \psi_{d r}+\frac{R_{r}}{\sigma L_{r}}\left(\frac{L_{m}}{L_{s}} \psi_{q s}-\psi_{q r}\right)
\end{aligned}
$$


$\frac{d \psi_{d r}}{d t}=v_{d r}+\left(\omega_{s}-\omega_{r}\right) \psi_{q r}+\frac{R_{r}}{\sigma L_{r}}\left(\frac{L_{m}}{L_{s}} \psi d s-\psi d r\right)$

The machine electric torque is represented as a function in stator and rotor fluxes as follows:

$T_{e}=\frac{1.5 \mathrm{P} L_{m}}{\sigma L_{s} L_{r}}\left(\psi_{q s} \psi_{d r}-\psi_{d s} \psi_{q r}\right)$

and the equation of motion are as given by equation (3)

\subsection{Fifth order model [8,9]:}

The voltage equations of the 5th order model are as follows:

$$
\left(\begin{array}{l}
V_{d s} \\
V_{q s} \\
V_{d r} \\
V_{q r}
\end{array}\right)=\left(\begin{array}{cccc}
R_{s} & 0 & 0 & 0 \\
0 & R_{s} & 0 & 0 \\
0 & 0 & R_{r} & 0 \\
0 & 0 & 0 & R_{r}
\end{array}\right)\left(\begin{array}{l}
i_{d s} \\
i_{q s} \\
i_{d r} \\
i_{q r}
\end{array}\right)+p\left(\begin{array}{l}
\psi_{d s} \\
\psi_{q s} \\
\psi_{d r} \\
\psi_{q r}
\end{array}\right)+\left(\begin{array}{cccc}
0 & -\omega_{s} & 0 & 0 \\
\omega_{s} & 0 & 0 & 0 \\
0 & 0 & 0 & -\left(\omega_{s}-\omega_{r}\right) \\
0 & 0 & \left(\omega_{s}-\omega_{r}\right) & 0
\end{array}\right)\left(\begin{array}{l}
\psi_{d s} \\
\psi_{q s} \\
\psi_{d r} \\
\psi_{q r}
\end{array}\right)
$$

The relation between currents and flux linkages are given by

$$
\left(\begin{array}{l}
i_{d s} \\
i_{q s} \\
i d r \\
i \\
q r
\end{array}\right)=\frac{1}{\sigma}\left(\begin{array}{cccc}
\frac{1}{L_{s}} & 0 & \frac{-L_{m}}{L_{r} L_{s}} & 0 \\
0 & \frac{1}{L_{s}} & 0 & \frac{-L_{m}}{L_{r} L_{s}} \\
\frac{-L_{m}}{L_{r} L_{s}} & 0 & \frac{1}{L_{r}} & 0 \\
0 & \frac{-L_{m}}{L_{r} L_{s}} & 0 & \frac{1}{L_{r}}
\end{array}\right)\left(\begin{array}{l}
\psi_{d s} \\
\psi_{q s} \\
\psi_{d r} \\
\psi_{q r}
\end{array}\right)
$$

where $\sigma=1-\frac{L_{m}^{2}}{L_{r} L_{s}}$

Using equations 1, 2 and 3, the following equation results 


$$
p\left(\begin{array}{c}
\psi_{d s} \\
\psi_{q s} \\
\psi_{d r} \\
\psi_{q r}
\end{array}\right)=\left(\begin{array}{c}
V_{d s} \\
V_{q s} \\
V_{d r} \\
V_{q r}
\end{array}\right)+\frac{1}{\sigma}\left(\begin{array}{cccc}
\frac{-R_{s}}{L_{s}} & 0 & \frac{R_{s} L_{m}}{L_{r}} & 0 \\
0 & \frac{-R_{s}}{L_{s}} & 0 & \frac{R_{s} L_{m}}{L_{r} L_{s}} \\
\frac{R_{r} L_{m}}{L_{r} L_{s}} & 0 & \frac{-R_{r}}{L_{r}} & 0 \\
0 & \frac{R_{r} L_{m}}{L_{r}} & 0 & \frac{-R_{r}}{L_{r}}
\end{array}\right)\left(\begin{array}{c}
\psi_{d s} \\
\psi_{d r} \\
\psi_{q r}
\end{array}\right)+\left(\begin{array}{cccc}
0 & \omega_{s} & 0 & 0 \\
-\omega_{s} & 0 & 0 & 0 \\
0 & 0 & 0 & \left(\omega_{s}-\omega_{r}\right) \\
0 & 0 & -\left(\omega_{s}-\omega_{r}\right) & 0
\end{array}\right)\left(\begin{array}{l}
\psi_{d s} \\
\psi_{q s} \\
\psi_{d r} \\
\psi_{q r}
\end{array}\right)(12)
$$

For the fifth order model, the machine electric torque and the equation of motion are as given by equations (9) and (3) respectively.

\section{Simulation studies:}

The $1^{\text {st }}, 3^{\text {rd }}$, and $5^{\text {th }}$ order models are used to determine the steady-state and transient behavior of the induction machine when connected to an infinite-bus The machine parameters are as given in Table (1) below:

.Table (1): Parameters of the Machine Under Study

\begin{tabular}{|l|l|l|}
\hline Power & $0.85 \mathrm{MVA}$ & \\
\hline Voltage L-L & $0.69 \mathrm{kV}$ & \\
\hline Stator resistance & 0.00332 & $0.00593 \mathrm{PU}$ \\
\hline Stator inductance & $0.000080 \mathrm{H}$ & $0.0453 \mathrm{PU}$ \\
\hline Magnetizing inductance & $0.0064 \mathrm{H}$ & $3.5945 \mathrm{PU}$ \\
\hline Rotor resistance (referred to stator) & 0.00278 & $0.00496 \mathrm{PU}$ \\
\hline Rotor inductance (referred to stator) & $0.00011 \mathrm{H}$ & $0.063 \mathrm{PU}$ \\
\hline
\end{tabular}

\subsection{Steady-state Simulation Results:}

When an induction machine is used, for example, for wind power generation, it can be a fixed speed machine with its rotor windings are normally shorted (i.e., $\mathrm{V}_{\mathrm{qr}}=\mathrm{V}_{\mathrm{dr}}=0$ ), or a doubly fed induction machine (DFIM) whose performance is affected by the injected rotor voltages $\mathrm{V}_{\mathrm{qr}}$ and $\mathrm{V}_{\mathrm{dr}}$. In this paper, the steady-state simulation study is conducted on a DFIM by keeping the value of either $\mathrm{V}_{\mathrm{qr}}$ or $\mathrm{V}_{\mathrm{dr}}$ component constant while varying the other one. Figs. 1-6 show the steadystate performance of a doubly fed induction machine when varying the slip from negative values (super synchronous speed) to positive values (sub synchronous speed). The simulation results in- 
dicate the followings:

1. increase of $\mathrm{V}_{\mathrm{q}}$ can result in the expansion of DFIM torque and real power characteristics for its generating mode, it also results in more inductive reactive power needed by the DFIM,

2. the increase of $V_{d}$ not only shifts DFIM torque and real power characteristics to its generating mode but also reduce the DFIM inductive reactive power and even could change it to capacitive, and

3. the increase of $\mathrm{V}_{\mathrm{d}}$ negatively shrinks the DFIM torque and real power characteristics for its generating mode and results in more inductive reactive power need.

It can be concluded from the above analysis that proper coordination between both $\mathrm{V}_{\mathrm{q}}$ and $\mathrm{V}_{\mathrm{d}}$ components of the DFIM injected rotor voltage results in optimal operation of DFIM in terms of torque, real power and reactive power.

\subsection{Transient Simulation Results:}

Both the $3^{\text {rd }}$ and $5^{\text {th }}$ order models are simulated using the PSCAD/EMTDC software. The transient performance is obtained when the machine is assumed operating as an induction generator: (a) under normal conditions and supplying its rated power to the infinite-bus, or (b) when it is subjected to a 3 -phase fault at its terminals.

Figs. 7 and 8 display the simulation results of case (a), where the $3^{\text {rd }}$ and the $5^{\text {th }}$ order models represent the induction generator when it is starting from standstill and supplying its rated power to the infinite-bus. On the other hand, Figs. (9-14) show the simulation results for case (b) when the induction generator is subjected to a 3-phase fault at its terminals. From these results, the following comments have been noted:

1. Both models yield almost the same steady-state values for the different variables. However, the magnitude of the currents predicted by the $3^{\text {rd }}$ order model is slightly less than that predicted by the $5^{\text {th }}$ order model. The magnitude of the machine currents is important for the evaluation of wind turbine protection system.

2. Following the starting instant, the $5^{\text {th }}$ order model exhibits transient oscillations which do not exist in the response of the $3^{\text {rd }}$ order model.

3. The $3^{\text {rd }}$ order model requires less time (transient period) to reach steady-state than that required by the $5^{\text {th }}$ order model.

4. The $3^{\text {rd }}$ order model exhibits unstable operation following the occurrence of the 3-phase short circuit fault, Figs(12 and 14),when the fault duration exceeds $0.33 \mathrm{~s}$. On the other hand, the $5^{\text {th }}$ order model shows stable operation, Figs(12 and 13). This result proves that one cannot rely on the accuracy of the dynamic response of the $3^{\text {rd }}$ order model. The difference in response can be attributed to the damping effect produced by the stator transients, which has been neglected in the $3^{\text {rd }}$ order model. 


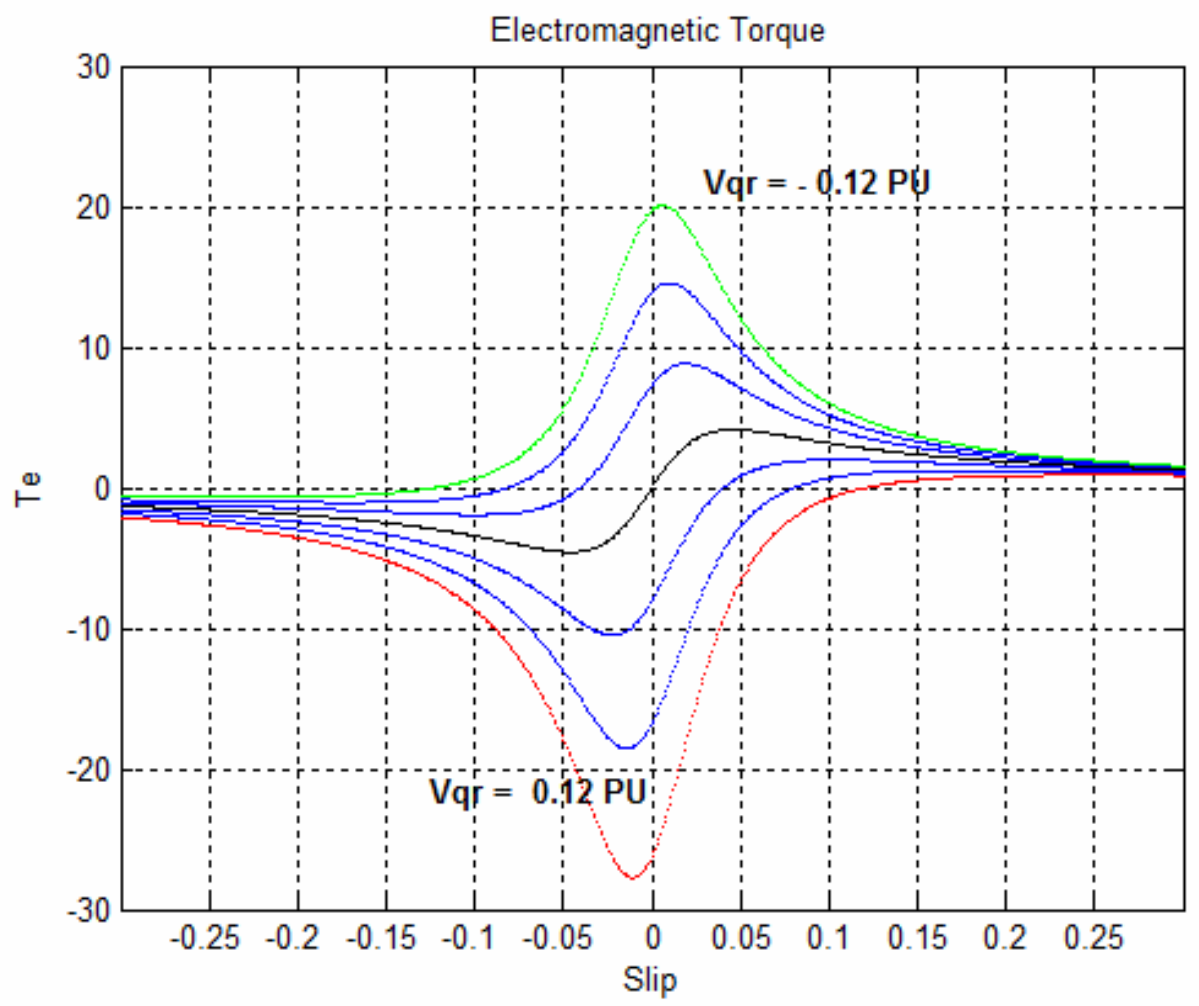

Fig. 1 Electromagnetic Torque versus Slip For variable $V_{q r}\left(V_{d r}=0\right)$

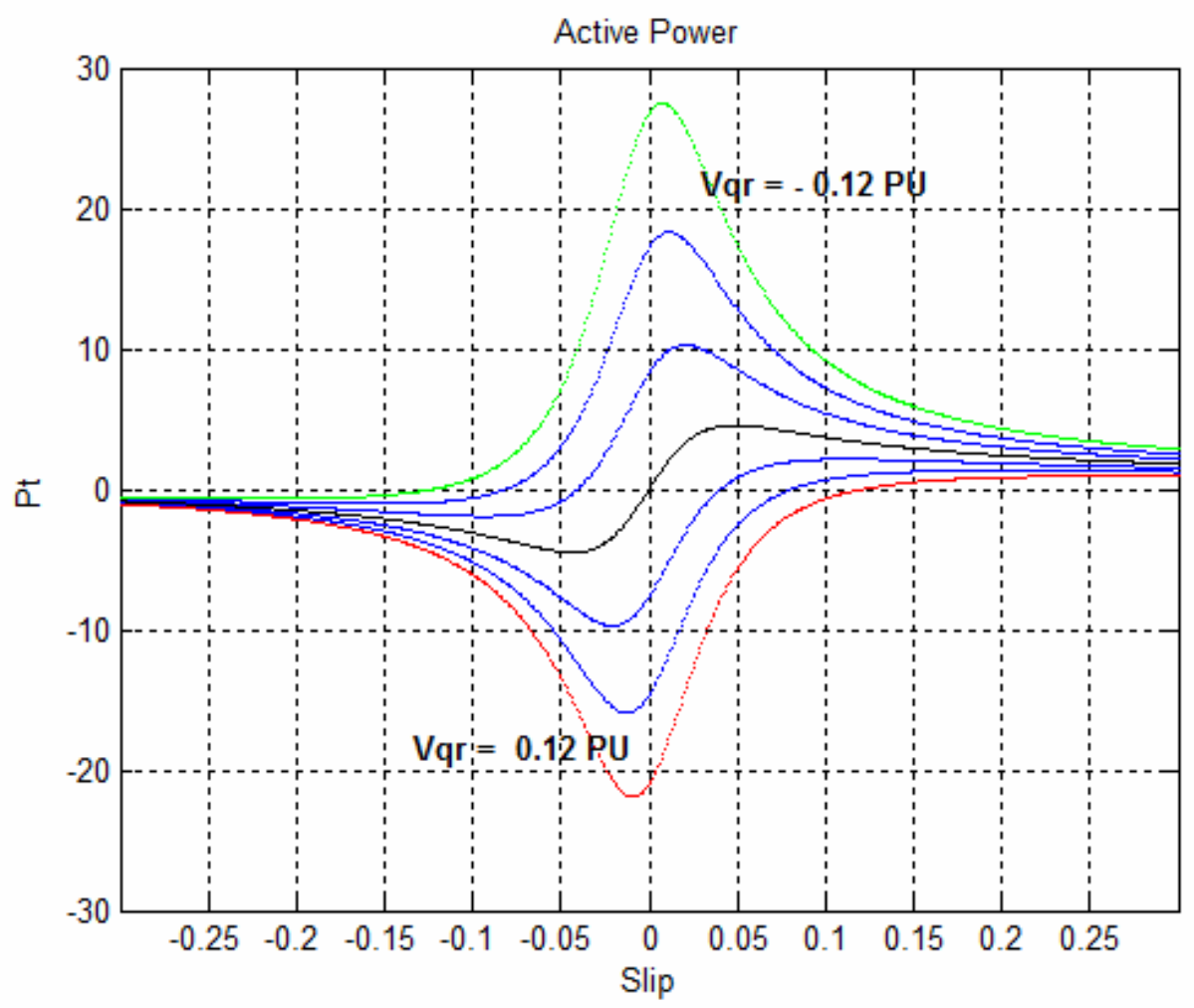

Fig. 2 Active Power versus Slip For variable Vqr $(V d r=0)$ 


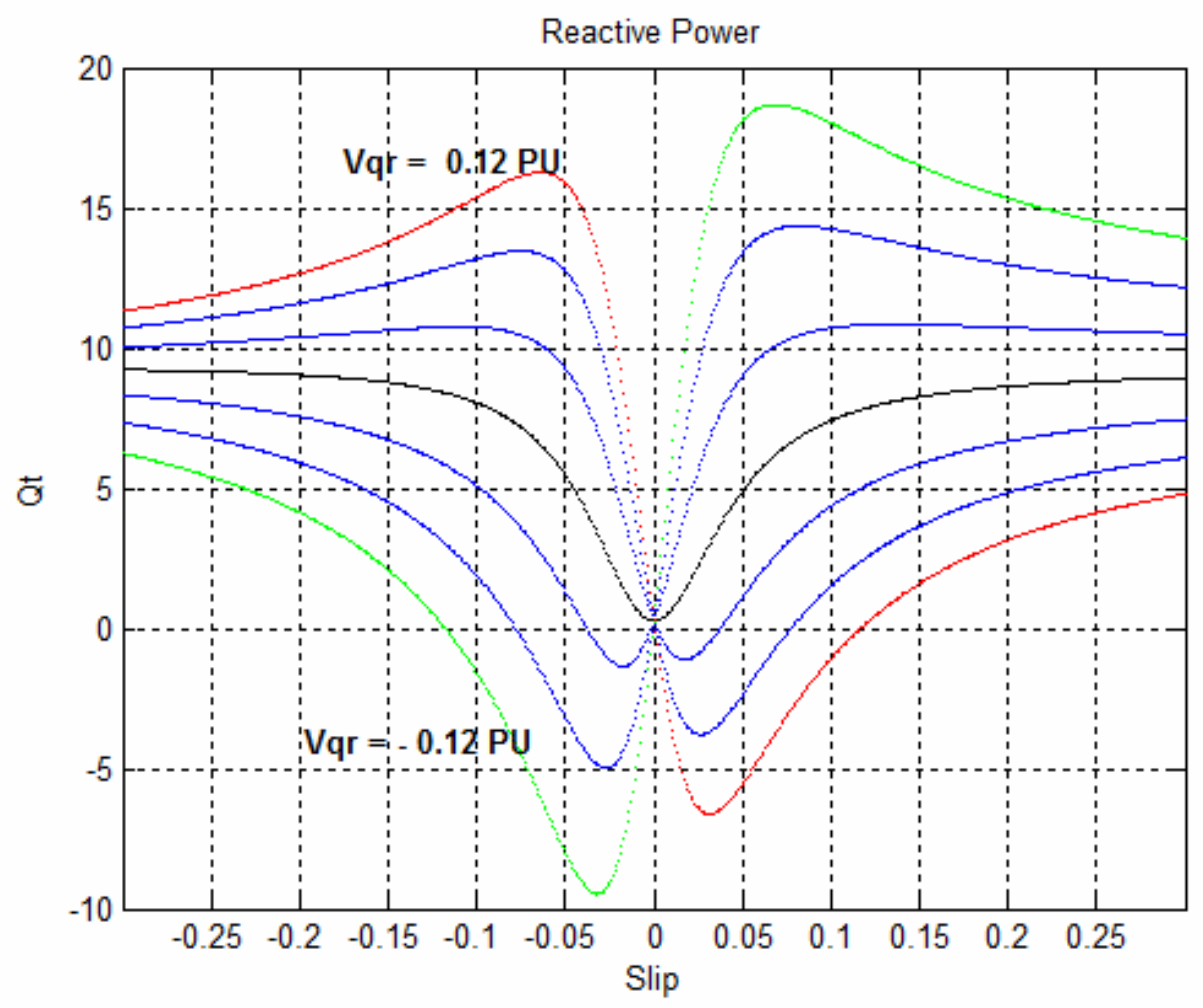

Fig. 3 Reactive Power versus Slip For variable $V_{q r}\left(V_{d r}=0\right)$

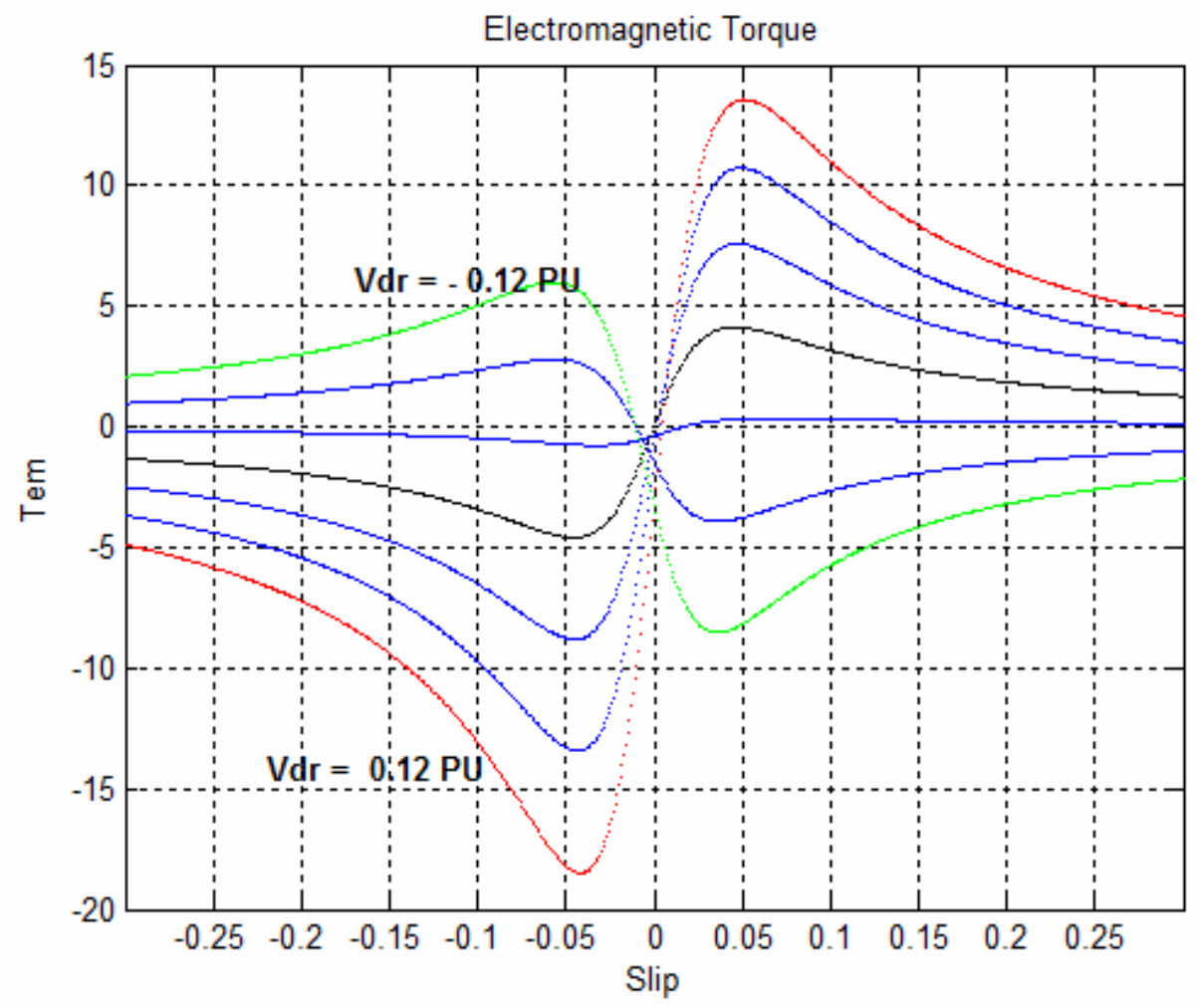

Fig. 4 Electromagnetic Torque versus Slip For variable Vdr $(V q r=0)$ 


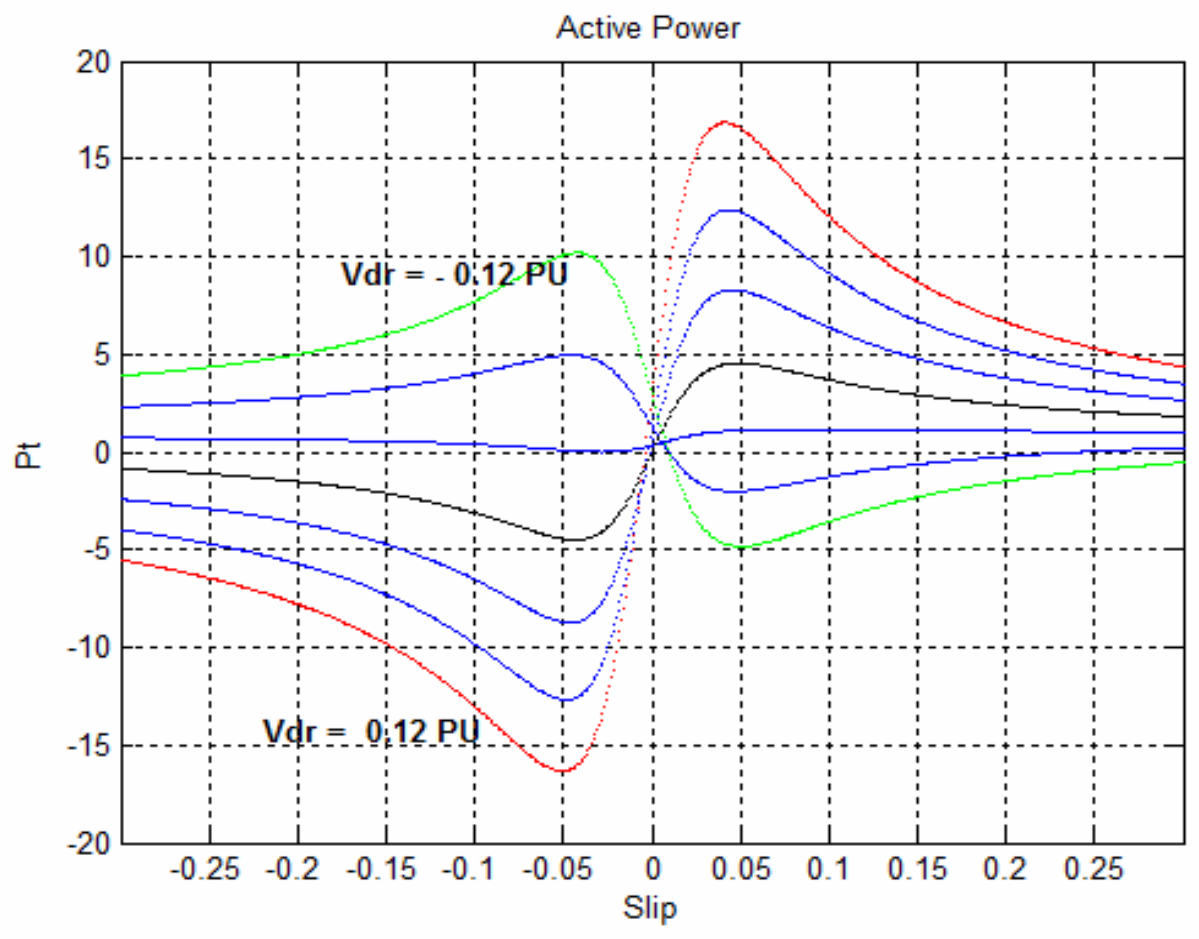

Fig. 5 Active Power versus Slip For variable Vdr $(V q r=0)$

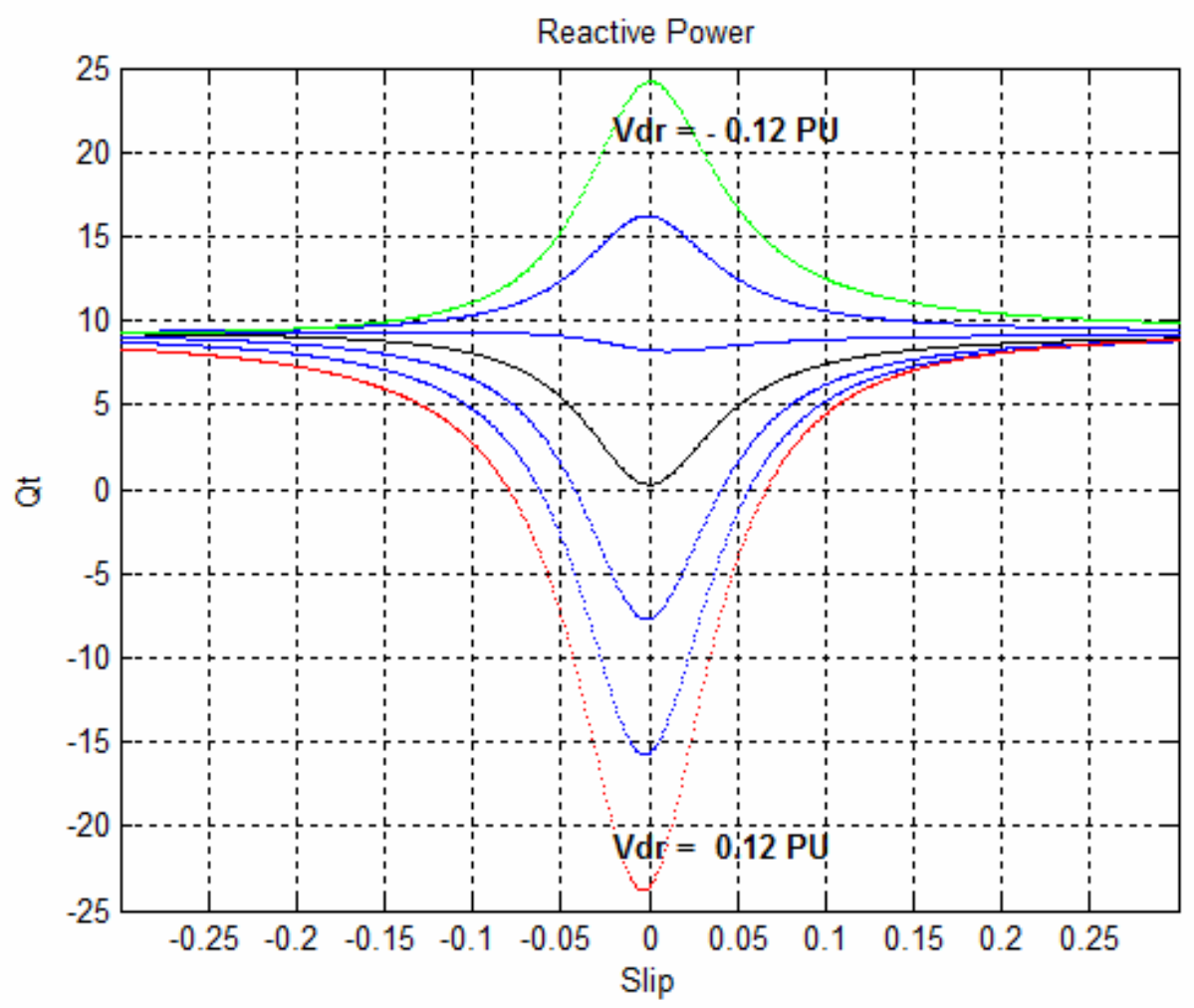

Fig. 6 Reactive Power versus Slip For variable $V_{d r}\left(V_{q r}=0\right)$ 

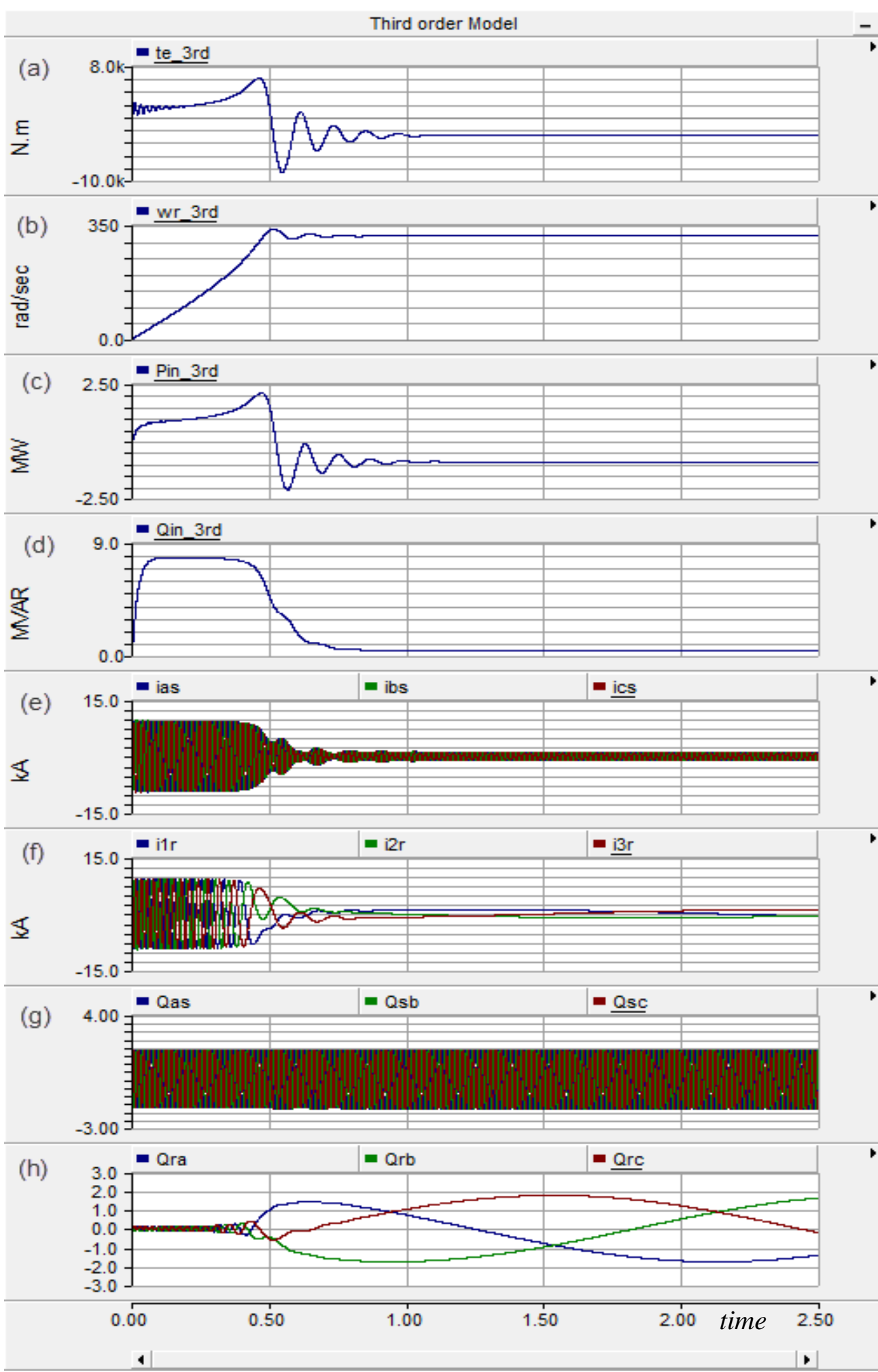

Fig. 7 Third order model characteristics

(a) Electromagnetic torque (b) Rotor speed (c) Active Power
(e) Stator current
(f) Rotor current
(g) Stator flux
(h) Rotor Flux

(d) Reactive Power 

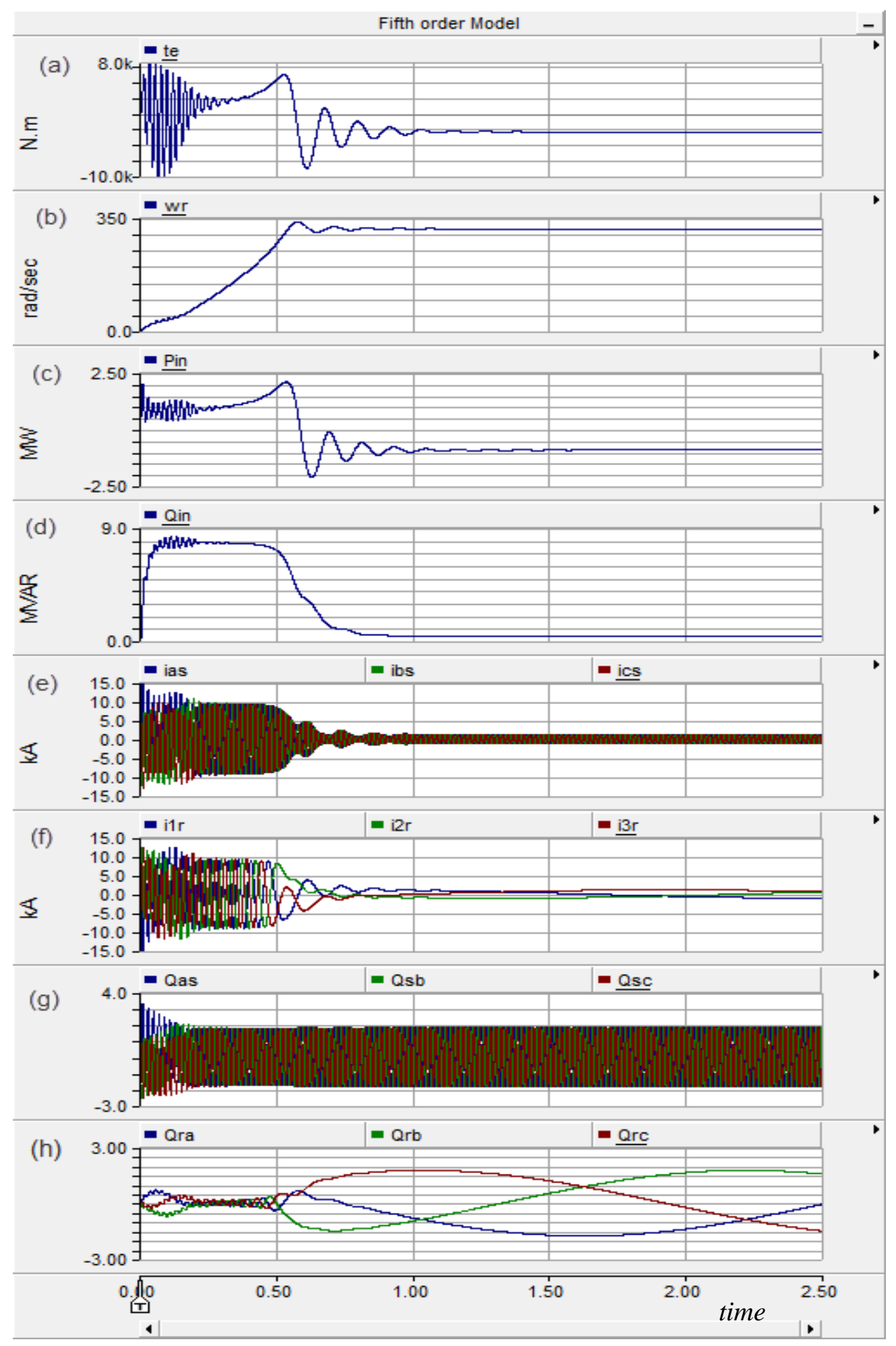

Fig. 8 Fifth order model characteristics (a) Electromagnetic torque (b) Rotor speed (c) Active Power
(e) Stator current
(f) Rotor current
(g) Stator flux
(h) Rotor Flux

(d) Reactive Power 
Proceedings of the $\boldsymbol{8}^{\text {th }}$ ICEENG Conference, 29-31 May, 2012

EE248- 12

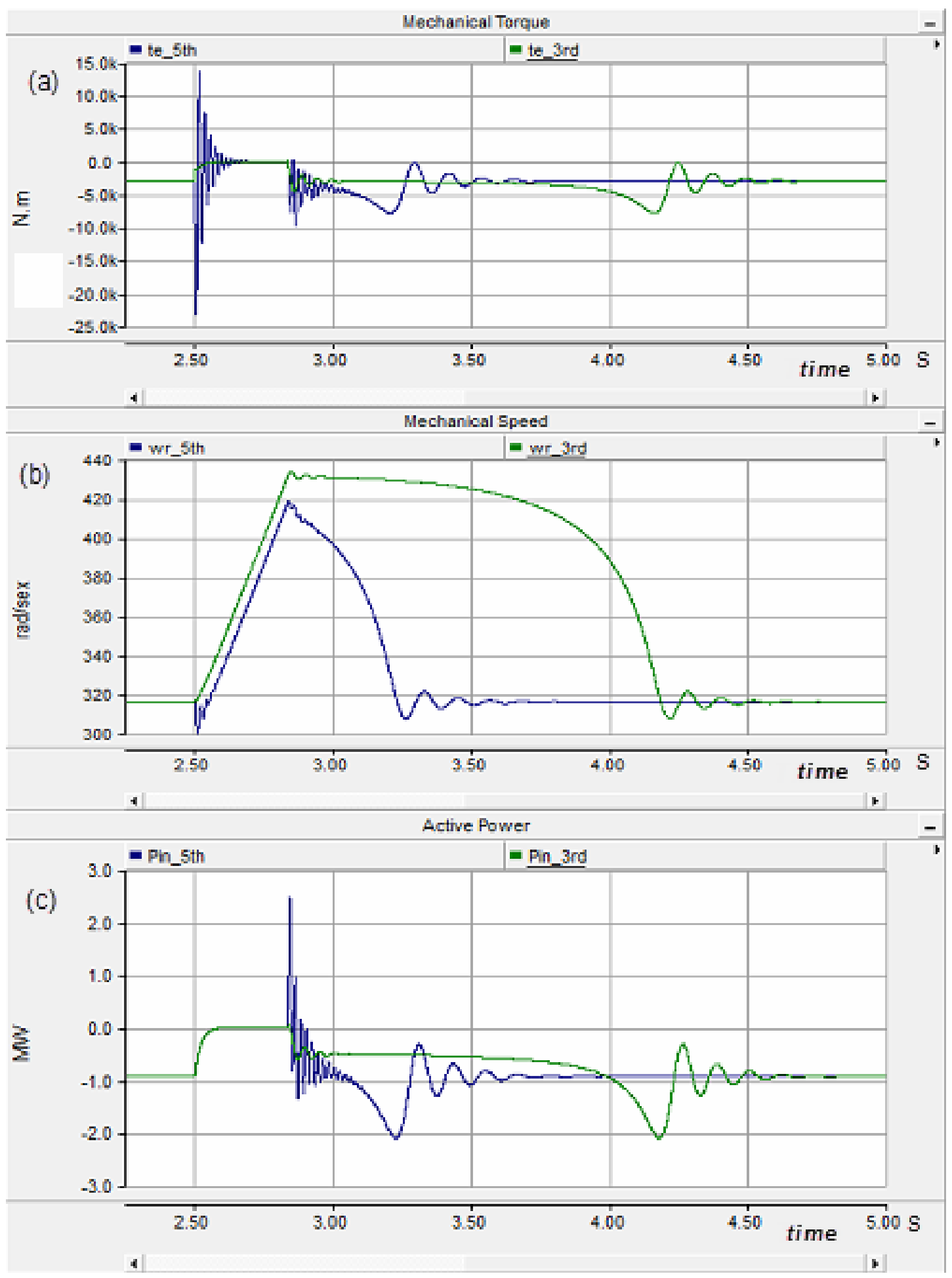

Fig. 9 Transient behavior of $3^{\text {rd }}$ and $5^{\text {th }}$ order models following sudden short circuit fault (fault duration $=0.33 \mathrm{~s}$ )
(a) Electromagnetic torque
(b) Rotor speed
(c) Active Power 


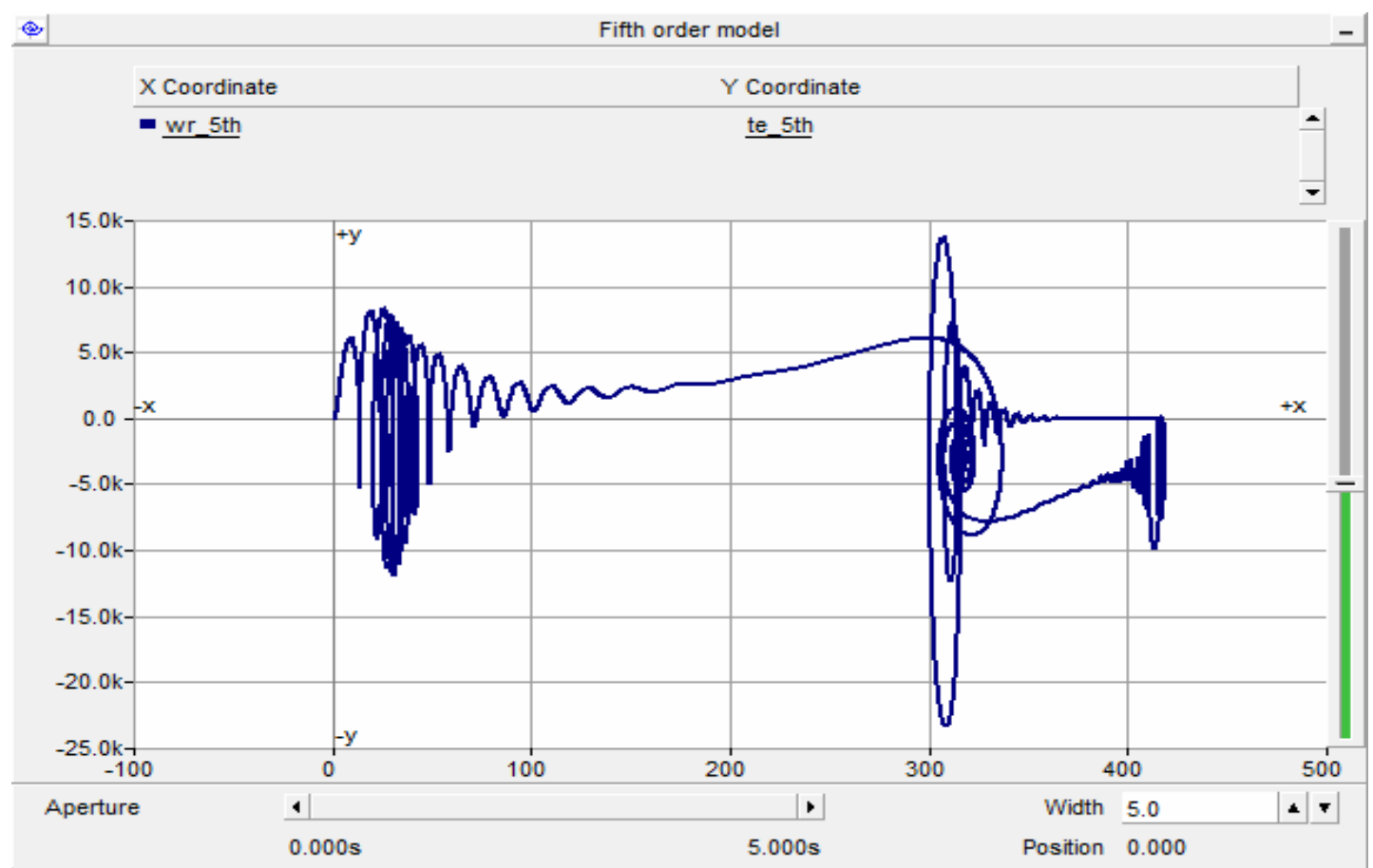

Fig. 10 Speed-torque Characteristics of $5^{\text {th }}$ order model during short circuit fault

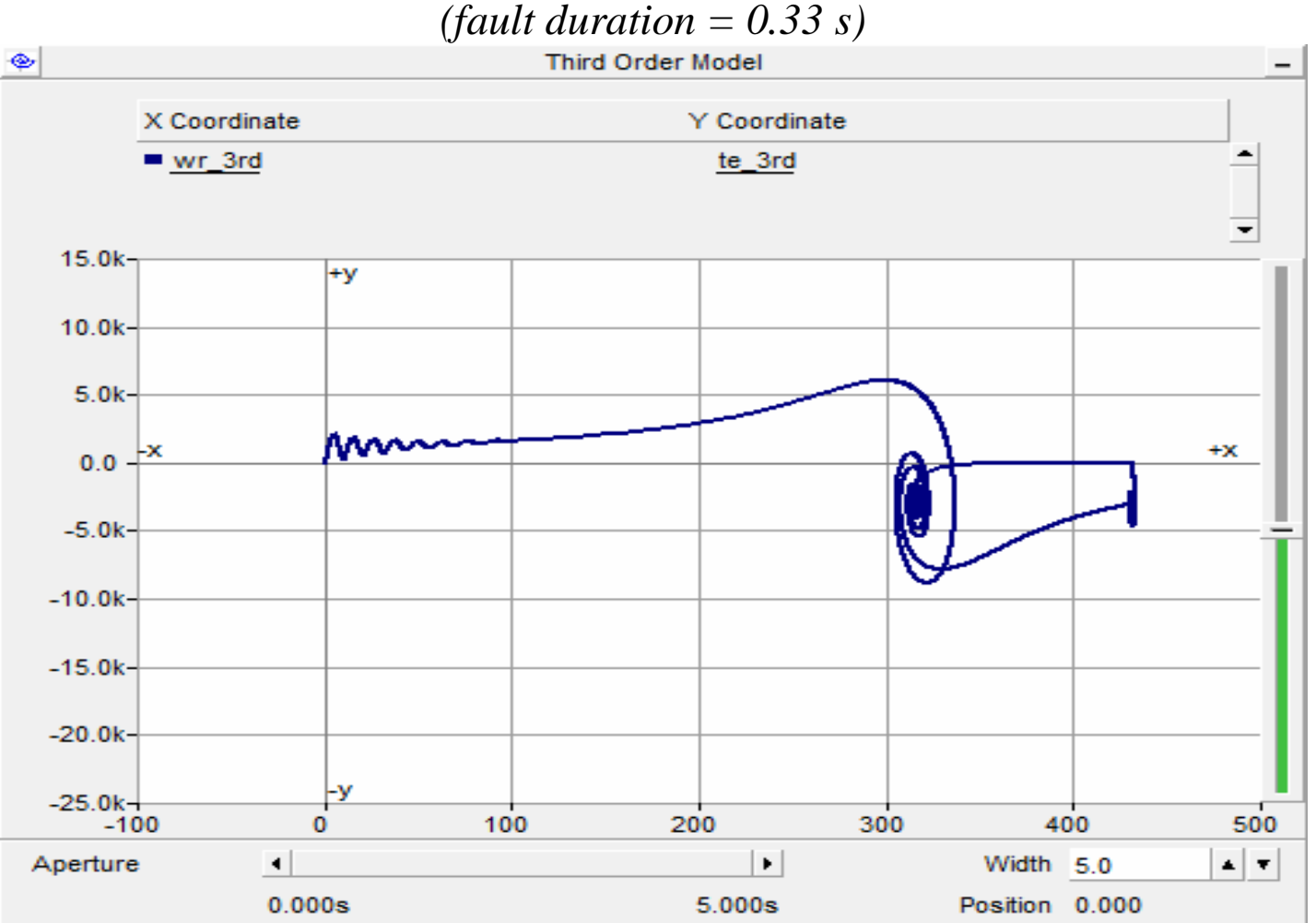

Fig. 11 Speed-torque Characteristics of $3^{\text {th }}$ order model during short circuit fault (fault duration $=0.33 \mathrm{~s}$ ) 
Proceedings of the $\boldsymbol{8}^{\text {th }}$ ICEENG Conference, 29-31 May, 2012

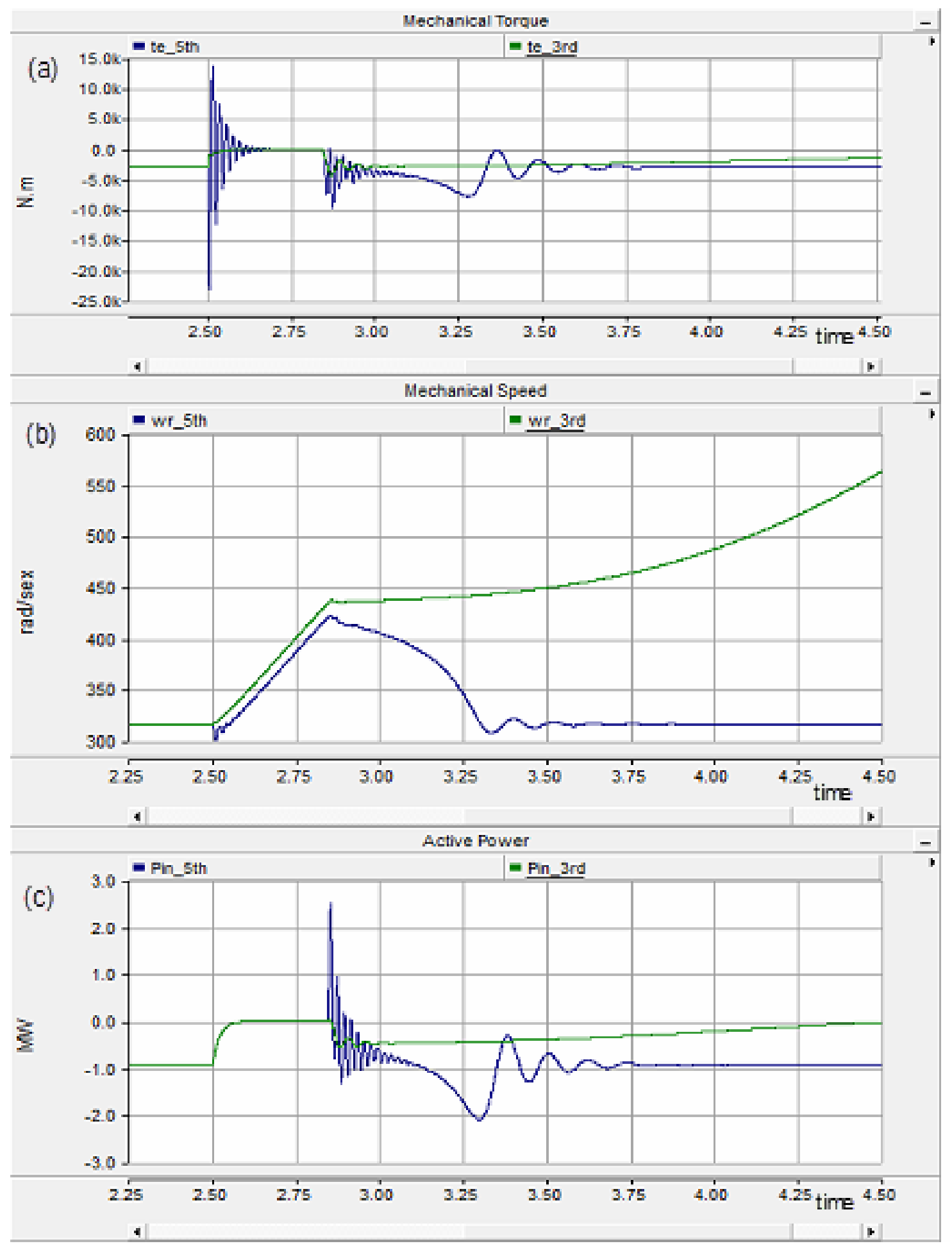

Fig. 12 Transient behavior of $3^{\text {rd }}$ and $5^{\text {th }}$ order models following sudden short circuit fault (fault duration $=0.34 \mathrm{~s}$ )
(a) Electromagnetic torque
(b) Rotor speed
(c) Active Power 
Proceedings of the $\boldsymbol{8}^{\text {th }}$ ICEENG Conference, 29-31 May, 2012

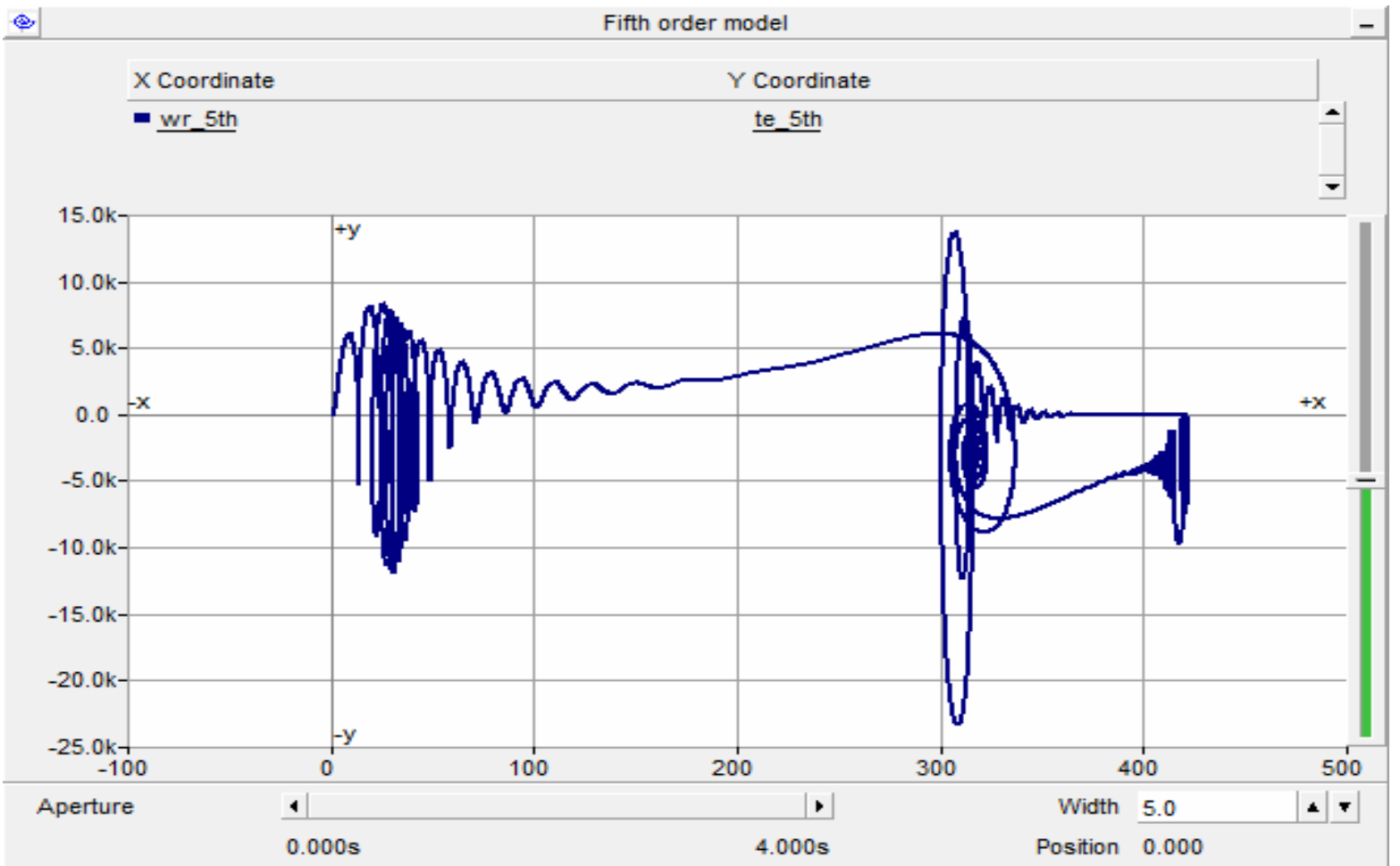

Fig. 13 Speed-torque Characteristics of $5^{\text {th }}$ order model during short circuit fault (fault duration $=0.34 \mathrm{~s}$ )

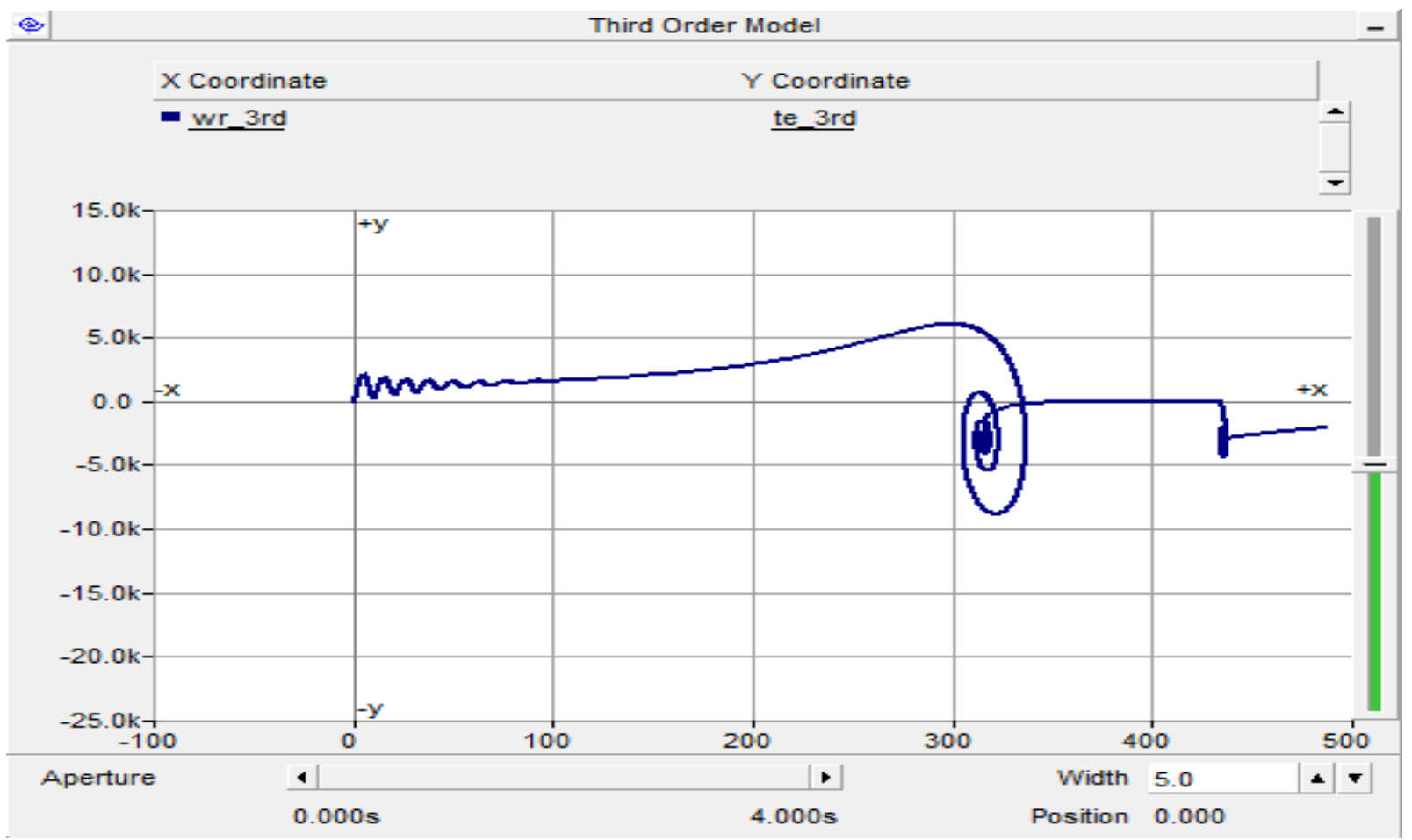

Fig. 14 Speed-torque Characteristics of $3^{\text {th }}$ order model during short circuit fault $($ fault duration $=0.34 \mathrm{~s})$ 


\section{Conclusions:}

This paper presents three different models named $1^{\text {st }}$ order, $3^{\text {rd }}$ order and $5^{\text {th }}$ order, capable of predicting the behaviour of induction machines. The three models can predict the steady-state performance. However, the $1^{\text {st }}$ order model is more suited for this purpose as it is straight forward, simpler, not time consuming and meantime provides results of similar accuracy to the other two models. The $3^{\text {rd }}$ and $5^{\text {th }}$ order models are more suited for the calculation of the machine transient response. However, the $5^{\text {th }}$ order model provides more accurate results as for the stability analysis, but it requires more computation time and simulation effort.

\section{References:}

[1] P. Kundur, "Power System Stability and Control", Book, McGraw-Hill, 1994.

[2] P. L. Dandeno and P. Kundur, "Stability Performance of 555 MVA Turboalternators - Digital Comparisons With System Operating Tests," IEEE Trans., Vol. PAS-93, No. 3, pp. 767-776, 1974.

[3] T. J. Hammons and D. J. Winning, "Comparison of Synchronous Machine Models in the Study of the Transient Behavior of Electrical Power Systems," Proc. IEE, Vol. 118, No. 10, pp. 1442-1458, 1971.

[4] P. C. Krause, "Analysis of Electric Machinery," Mc-Graw Hill, New York, 1986.

[5] C. M. Ong, "Dynamic Simulation of Electric Machinery," Upper Saddle River, NJ: Prentice-Hall, 1998.

[6] A. Mullance, and M. O'Malley, "The Inertial Response of InductionMachine-Based Wind Turbines," IEEE Trans., Vol. PAS -20, No. 3, August 2005, pp. 1496-1503.

[7] A. Feijoo, J. Cidras, and C. Carrillo, "A Third Order Model for the DoublyFed Induction Machine," Electric Power System Research, Vol. 56, pp. 121127, 2000.

[8] R. Fadaeinedjad, M. Moallem, and G. Moschopoulos, "Simulation of a Wind Turbine With Doubly Fed Induction Generator by FAST and Simulink", IEEE Trans. on Energy Conversion, Vol. 23, No. 2, pp. 690-700, June 2008.

[9] M. G. Gracia, M. P. Comech, J. Sallan, and A. Llombart, "Modeling Wind Farms for Grid Disturbance Studies," ScienceDirect, Renewable Energy, Vol. 33, pp. 2109-2121, 2008. 


\section{Nomenclatures:}

$\mathrm{V}_{\mathrm{ds}}, \mathrm{V}_{\mathrm{qs}}$ the d-and q-axis components of stator voltage,

$\mathrm{V}_{\mathrm{dr}}, \mathrm{V}_{\mathrm{qr}}$ the $\mathrm{d}$ - and q-axis components of rotor voltage,

$R_{s}, R_{r} \quad$ stator and rotor resistance respectively,

$i_{\mathrm{ds}}, i_{\mathrm{qs}}$

$i_{\mathrm{dr}}, i_{\mathrm{qr}}$

$\Psi_{\mathrm{ds}}, \Psi_{\mathrm{qs}}$ the d-and q-axis components of stator current,

$\Psi_{\mathrm{dr}}, \Psi_{\mathrm{qr}}$ the $\mathrm{d}$ - and q-axis components of rotor current,

$\omega_{\mathrm{s}}$ stator flux in $\mathrm{d}$ - and q-axis respectively,

$\omega_{\mathrm{r}}$

$\mathrm{L}_{\mathrm{s}}, \mathrm{L}_{\mathrm{r}}$

$\mathrm{L}_{\mathrm{m}}$

$\mathrm{X}_{\mathrm{s}}, \mathrm{X}_{\mathrm{r}}$

$\mathrm{X}_{\mathrm{m}}$

$\mathrm{P}$

rotor flux in d- and q-axis respectively,

stator angular electrical frequency,

rotor angular electrical speed,

stator and rotor inductance respectively,

magnetizing inductance,

stator and rotor reactance respectively,

magnetizing Reactance,

numbers of pair of poles

$p \quad$ derivative with respect to time $(=d / d t)$

$\mathrm{T}_{e} \quad$ the electromechanical torque of the machine

$\mathrm{T}_{\mathrm{m}}$

the output mechanical torque of the machine

$\theta_{\mathrm{r}}$

$\mathrm{I}_{\mathrm{ds}}, \mathrm{I}_{\mathrm{qs}}$

$I_{\mathrm{dr}}, \mathrm{I}_{\mathrm{qr}}$

$\mathrm{S}$

the rotor angle

the $\mathrm{d}$ - and q-axis components of steady-state stator current,

the $\mathrm{d}$ - and q-axis components of steady-state rotor current,

$\sigma$

the slip of the asynchronous machine,

$\sigma$

the leakage reactance 